ORIGINAL ARTICLE

\title{
The changing nature of the population of intensive-care patients
}

\author{
Fakhri Athari ${ }^{* 1,2}$, Ken M. Hillman ${ }^{1,2}$, Steven A. Frost ${ }^{2,3}$ \\ ${ }^{1}$ Simpson Centre for Health Services Research, Ingham Institute of Applied Medical Research, SWS Clinical School, University of \\ New South Wales, Australia \\ ${ }^{2}$ Intensive Care, Liverpool Hospital, Australia \\ ${ }^{3}$ School of Nursing and Midwifery, University of Western Sydney, Australia
}

Received: January 2, 2018

Accepted: February 6, 2018

Online Published: February 8, 2018

DOI: $10.5430 /$ jha.v7n2p1

URL: https://doi.org/10.5430/jha.v7n2p1

\begin{abstract}
Background: The increase in the number of Australia's frail, very elderly ( $\geq 80$ years of age) population will have an impact on admissions to intensive care. As the number of very elderly patients increase, it will be important to have information about what the impact of increasing age will have on aspects such as: the impact of age and chronic health conditions on intensive care treatment, and the impact on prognosis in the short and longer-term as well as how we should be involving the very elderly in determining their own goals of care.

Objective: To evaluate the long-term trend in the rates of the very elderly ( $\geq 80$ years of age) admitted to intensive care, as well as describe their chronic health conditions, length of stay, and mortality rates.

Methods: This study was a retrospective review that used a database from a 40-bed, multidisciplinary, adult intensive care unit (ICU), located in South-Western Sydney, Australia. The setting is an 877-bed tertiary hospital that has medical and surgical specialties; including a referral trauma unit, with approximately 80,000 admissions a year. Data were acquired over 15-years, from January 1st, 2000 to December 31st, 2015.

Results: Data were available for 32,796 patients, and of these, $4,137(12.5 \%)$ were aged $\geq 80$ years. The percentage of the very elderly admitted to ICU progressively increased from $8.6 \%$ in 2000 to $(14.5 \%$ in $2015, p<.001)$. Overall, the median length of stay (LOS) in the ICU was 2-days (interquartile range: 1.2-4.1), and increased from 2.0 to 2.3 ( $p<.001$ ). Similarly, the median hospital LOS increased over time from 9 to 11 days $(p<.001)$. Intensive care and hospital death rates decreased over time from $19.9 \%$ to $9.8 \%(p<.001)$, and $31.8 \%$ to $19.9 \%(p<.001)$, respectively. The majority of the very elderly were admitted from the emergency department (ED) (38.1\%), other sources of admission being from the operating theatres (OT) (33.5\%), and the general ward $(18.1 \%)$.

Conclusions: The number and percentage of very elderly patients being managed in ICU is increasing, representing a different population from the one that much of our practice has been previously based. For example, we may need to review the way we estimate severity of illness on admission to the ICU with more weight given to the chronic health component of the very elderly. The acute indications for admission to ICU such as falls and infections are relatively straightforward to manage and usually have a good outcome. However, because age and the chronic health status of the very elderly are largely progressive and irreversible, we as health care professionals working in intensive care may have to consider longer-term post hospital outcomes as a basis for evaluating the effectiveness of the interventions in ICU.
\end{abstract}

Key Words: Very elderly, Ageing, Co-morbidities, Long-term outcome, Intensive care, Frailty

* Correspondence: Fakhri Athari; Email: f.athari@student.unws.edu.au; Address: Simpson Centre for Health Services Research, Ingham Institute of Applied Medical Research, SWS Clinical School, University of New South Wales, Australia.

Published by Sciedu Press 


\section{INTRODUCTION}

The global increase in the ageing population has been accelerating rapidly. ${ }^{[1]}$ It is estimated by 2050 , the world's population will have increased by two billion. ${ }^{[2]}$ The very elderly population ( $\geq 80$ years), ${ }^{[2,3]}$ are the most rapidly growing age group and are expected to increase from one in six currently, to one in five by $2050 .{ }^{[2,3]}$ The increased use of hospital and intensive care unit (ICU) resources is expected to increase substantially over the next 10 to 20 years as the very elderly population increases even more. ${ }^{[4]}$ There have been some studies showing the increasing trend of age in ICUs ${ }^{[5-8]}$ but little specific information about long-term ageing trends in the Australian ICU setting. The aim of this study was to describe the long-term trends in the rates of the very elderly in an Australian ICU, as well as the, clinical characteristics, co-morbidities, admission source, and outcomes of the very elderly patients ( $\geq 80$ years of age), compared to other age groups.

\section{MATERIALS AND METHODS}

\subsection{Setting}

This retrospective study was undertaken at Liverpool Hospital, a 40-bed, multidisciplinary adult ICU in an 877-bed hospital that provides services for the South-Western Sydney Local Health District, in Sydney, Australia. Data were obtained from the adult database provided by the Australian and New Zealand Intensive Care Society (ANZICS), which routinely collects data for ICUs in both countries. The study period was January 1st 2000 to December 31st, 2015. Very elderly admissions were defined as those aged 80 -years or older, at the time of ICU admission.

\subsection{Patients' specific and outcome data}

The following variables were extracted for all patients: age, sex, pre-existing disease status (co-morbidities), date of ICU admission and discharge destination, ICU admission source, ICU interventions, the severity of diseases the Acute Physiology and Chronic Health Evaluation (APACHE- II) ${ }^{[9]}$ scores and the Simplified Acute Physiology Scores (SAPS-II) ${ }^{[10]}$ as well as in-hospital and ICU mortality rates.

\subsection{Statistical analysis}

All data were analysed using SPSS version 24.1 (IBM Co. Armonk NY, USA, 2017). Categorical data are presented as frequencies and percentages. Continuous variables are presented using mean, standard deviation or median and interquartile range, where appropriate. Admission periods January 1st 2000 to December 31st, 2015 were divided into fouryear intervals. Age was divided into the following groups $<$ $20,20-39,40-59,60-79,80+$. Trends in the rate of admission to ICU over the study period, were analysed using the $\chi^{2}$ test for trend. Linear regression was applied to the natural logarithmic transformation of the yearly admission percentages of each age group to estimate average yearly percentage rate of change. Differences between admission period intervals for patient characteristics, admission sources, pre-existing disease statuses and outcomes were assessed using ANOVA, Chi-squared test, or Kruskal-Wallis where appropriate. The level of statistical significance was set at 0.05 .

\section{RESUltS}

During the 15-year study period, there were 32,796 ICU admissions (excluding re-admissions) of patients aged $\geq 18$ years (see Table 1). The overall total number of ICU admissions for very elderly patients was 4,137 (12.5\%). The percentage of the very elderly patients admitted to ICU between 2000 to 2015 increased from $8.6 \%$ to $14.5 \%$ [95\% Confidence Interval (CI): 4.5 (3.1 to 6.0); $p<.001$ ], with an annual rate of change of $4.5 \%$ per year (95\% CI: 3.1 to 6.0).

Table 1. Rates of ICU admissions for all age groups from 2000 to 2015

\begin{tabular}{|c|c|c|c|c|c|c|}
\hline \multirow{2}{*}{$\begin{array}{l}\text { Age } \\
\text { group }\end{array}$} & \multirow{2}{*}{$\begin{array}{l}2000-2003 \\
\text { n }(\%)\end{array}$} & \multicolumn{2}{|c|}{ Admission period } & \multirow{2}{*}{$\begin{array}{l}\text { 2012-2015 } \\
\text { n (\%) }\end{array}$} & \multirow[b]{2}{*}{$p$-value ${ }^{*}$} & \multirow{2}{*}{$\begin{array}{l}\text { Rate of change }^{\#} \\
\%(95 \% \mathrm{CI})\end{array}$} \\
\hline & & $\begin{array}{l}\text { 2004-2007 } \\
\text { n }(\%)\end{array}$ & $\begin{array}{l}\text { 2008-2011 } \\
\text { n }(\%)\end{array}$ & & & \\
\hline$<20$ & $137(1.9)$ & $75(1.1)$ & $100(1.2)$ & $103(1.0)$ & $<.001$ & $-4.5(-6.6$ to -2.4$)$ \\
\hline $20-39$ & $1,180(16.2)$ & $993(14.4)$ & $1,053(12.7)$ & $1,209(11.7)$ & $<.001$ & $-2.8(-3.5$ to -2.1$)$ \\
\hline $40-59$ & $2,021(27.8)$ & 1,905 (27.7) & 2,209 (26.7) & 2,767 (26.7) & .159 & $-0.4(0.9$ to 0.2$)$ \\
\hline $60-79$ & $3,313(45.5)$ & $3,111(45.2)$ & $3,695(44.7)$ & $4,788(46.2)$ & .555 & $0.01(-0.2$ to 0.4$)$ \\
\hline $80+$ & $629(8.6)$ & 802 (11.6) & $1,201(14.6)$ & $1,505(14.5)$ & $<.001$ & 4.5 (3.1 to 6.0$)$ \\
\hline Total & $7,280(22.2)$ & $6,886(21.0)$ & $8,258(25.2)$ & $10,372(31.6)$ & & \\
\hline
\end{tabular}

Note. ${ }^{*} p$-value from chi-squared test for trend; ${ }^{*}$ Average yearly trend was assessed using linear regression applied to the natural logarithmic transformation of the yearly admission percentages 
Table 2. Characteristics, hospital and ICU outcomes of very elderly patients ( $\geq 80$ years), their admission sources and pre-existing conditions, for admission to ICU between 2000 to 2015

\begin{tabular}{|c|c|c|c|c|c|c|}
\hline & \multicolumn{4}{|c|}{ Admission Period } & \multirow[b]{2}{*}{$\begin{array}{l}\text { Overall } \\
(N=4,137)\end{array}$} & \multirow[b]{2}{*}{$p$-value } \\
\hline & $\begin{array}{l}2000-2003 \\
(N=629)\end{array}$ & $\begin{array}{l}\text { 2004-2007 } \\
(\mathrm{N}=\mathbf{8 0 2})\end{array}$ & $\begin{array}{l}2008-2011 \\
(N=1,201)\end{array}$ & $\begin{array}{l}2012-2015 \\
(N=1,505)\end{array}$ & & \\
\hline Age (yr), mean $(S D)$ & $83.9(4.0)$ & $83.7(3.6)$ & $84.3(3.7)$ & $84.4(3.7)$ & 3.7 & $<.001$ \\
\hline Male, n (\%) & $308(49.0)$ & $435(54.2)$ & $641(53.4)$ & $804(53.4)$ & 52.9 & .176 \\
\hline Apache II, median (IQR) & $18(14-23)$ & $17(13-23)$ & $17(13-22)$ & $17(13-22)$ & $17(13-22)$ & .053 \\
\hline SAPS II, median (IQR) & $39(30-51)$ & $39(30-52)$ & $38(31-48)$ & $38(31-48)$ & $38(31-49)$ & .012 \\
\hline \multicolumn{7}{|l|}{ Admission source to ICU } \\
\hline Admitted via ED, n (\%) & $158(25.2)$ & $255(31.8)$ & $474(39.6)$ & $688(45.7)$ & 38.1 & $<.001$ \\
\hline Admitted via other hospital, n (\%) & $59(9.4)$ & $70(8.7)$ & $40(3.3)$ & $53(3.5)$ & 5.4 & $<.001$ \\
\hline Ward, n (\%) & $153(24.4)$ & $208(25.9)$ & $295(24.6)$ & $293(19.5)$ & 18.1 & $<.001$ \\
\hline Operating Theatre, $\mathrm{n}(\%)$ & $256(40.9)$ & $269(33.5)$ & $389(32.5)$ & $471(31.3)$ & 33.5 & $<.001$ \\
\hline \multicolumn{7}{|l|}{ Pre-existing Disease Status } \\
\hline Chronic respiratory disease, $\mathrm{n}(\%)$ & $32(9.1)$ & $46(6.4)$ & $72(6.4)$ & $115(8.0)$ & 7.3 & $<.001$ \\
\hline Chronic cardiovascular disease, $\mathrm{n}(\%)$ & $71(18.8)$ & $57(7.9)$ & $86(7.7)$ & $134(9.3)$ & 9.5 & $<.001$ \\
\hline Immune Disease, $\mathrm{n}(\%)$ & $16(4.7)$ & $4(0.6)$ & $7(0.6)$ & $14(1.0)$ & 1.1 & $<.001$ \\
\hline Immunosuppressed & $4(1.2)$ & $4(0.6)$ & $26(2.3)$ & $44(3.1)$ & 2.2 & $<.001$ \\
\hline Cirrhosis Chronic Liver Disease & $4(1.2)$ & $11(1.6)$ & $4(0.4)$ & $12(0.8)$ & 0.9 & .047 \\
\hline Metastases & $13(3.9)$ & $22(3.2)$ & $37(3.3)$ & $49(3.4)$ & 3.4 & .948 \\
\hline Leukaemia Myeloma & $324(51.2)$ & $683(85.2)$ & $1,096(91.3)$ & $1,403(93.2)$ & 84.7 & $<.001$ \\
\hline Hepatic Failure & $0(0)$ & $1(0.1)$ & $1(0.1)$ & $0(0.0)$ & 1.0 & .533 \\
\hline IDDM & $13(3.9)$ & $24(3.4)$ & $63(5.6)$ & $72(5.0)$ & 4.8 & .147 \\
\hline Chronic Renal Failure & $10(3.0)$ & $22(3.2)$ & $37(3.3)$ & $39(2.7)$ & 3.0 & .830 \\
\hline Lymphoma & $0(0)$ & $8(1.2)$ & $10(0.9)$ & $6(0.4)$ & 0.7 & .076 \\
\hline \multicolumn{7}{|l|}{ Outcomes } \\
\hline $\begin{array}{l}\text { ICU length of stay (days), median } \\
\text { (IQR) }\end{array}$ & $2.0(0.9-3.8)$ & $2.4(1.2-4.1)$ & $2.6(1.4-4.3)$ & $2.3(1.3-4.1)$ & $2.3(1.2-4.1)$ & $<.001$ \\
\hline $\begin{array}{l}\text { Hospital length of stay (days), } \\
\text { median (IQR) }\end{array}$ & $9.0(4.0-18.0)$ & $11.0(5.0-20.0)$ & $11.0(6.0-22.0)$ & $11.0(6.0-21.0)$ & $11(6.0-20.0)$ & $<.001$ \\
\hline ICU death, n (\%) & $125(19.9)$ & $152(19.0)$ & $155(13.0)$ & $146(9.8)$ & 14.1 & $<.001$ \\
\hline Hospital death, n (\%) & $200(31.8)$ & $239(29.8)$ & $305(25.5)$ & $300(19.9)$ & 25.2 & $<.001$ \\
\hline
\end{tabular}

Note. $S D=$ Standard Deviation; $\mathrm{IQR}=$ Interquartile range; ${ }^{*} p$-value from ANOVA, chi-square or Kruskal-Wallis test for continuous, categorical or skewed data, respectively

The mean age of the very elderly admitted to ICU was 84.1 years $(S D)$ and $52.9 \%$ were male (see Table 2). The trend in age of the very elderly increased over the study period (from 83.9 to 84.4 years, $p<.001)$. The rates of patients admitted to ICU from the emergency department (ED) increased from $25.2 \%$ to $45.7 \%(p<.001)$. Admissions decreased from other hospitals, wards and operating theatres (OT) from (9.4\% to $3.5 \%, 24.4 \%$ to $19.5 \%, 40.9 \%$ to $31.3 \%$ respectively; all $p$-values $<.001)$. Overall, the most frequent pre-existing condition among this population was chronic cardiovascular disease $(9.5 \%)$, followed by chronic respiratory disease (7.3\%), and diabetes mellitus Type I (IDDM) (4.8\%). Over the period the rates of leukaemia/myeloma and immunosuppressed related diseases in the very elderly increased (from $51.2 \%$ to $93.2 \%, p<.001$, and $1.2 \%$ to $3.1 \%, p<.001$, respectively); while immune related diseases decreased (from $4.7 \%$ to $1.0 \% ; p<.001)$. Overall, the median length of stay (LOS) in the ICU increased over the study period from 2.0 to $2.3, p<$ .001. Similarly, the median hospital LOS increased over time from 9 to 11 days $(p<.001)$. Hospital and ICU death rates decreased over time from $19.9 \%$ to $9.8 \%(p<.001)$, and $31.8 \%$ to $19.9 \%(p<.001)$, respectively. Compared to females, males had significantly higher rates of ICU deaths (14.6\%, $p<.001)$ and hospital death rates $(24.7 \%, p<.001)$.

Data on ICU interventions were available for 2,414 (for the $72 \%$ of ICU admissions for the very elderly). Of these 852 $(20.6 \%)$ required arterial line, and $860(20.8 \%)$ required invasive ventilation during their ICU stay (see Table 3 ).

Table 4 presented the comparison of co-morbidities between those over 80 and those under 80 admitted to ICU showed that co-morbidities such as chronic respiratory dis- 
ease, chronic cardiovascular diseases, were higher compared to the aged group (60-79 years and 40-59 years). However IDDM and chronic renal failure rates were higher in younger patients compared to the very elderly patients.

\section{Discussion}

This study evaluated the changing age-related nature of the patients admitted to a large Australian ICU. It found that while ICU admission rates for patients aged 40 to 79 remained constant over the 15 years from 2000 to 2015, the absolute numbers $(629$ to $1,505, p<.001)$ and rates $(8.6 \%$ to $14.5 \%, p<.001$ ) for the very elderly ( $\geq 80$ years) increased over that same period. The very elderly also had more comorbidities and an increased in-hospital LOS in both ICU and hospital.

The reasons for the increase in the number of admissions of very elderly people to the ICU may simply be related to the increase in the age of the general population, ${ }^{[7,8,11]}$ accompanied by an expansion of intensive care services; ${ }^{[12]}$ an increase in the public expectations of modern medicine; ${ }^{[13,14]}$ and the general trend of accepting more patients in the ICU regardless of their age. ${ }^{[15]}$ There didn't appear to be a dif- ference in the level of illness as measured by APACHE II or SAPS II which is, weighted more to the level of acute abnormalities. The increased level of intervention was related more to the level of chronic illness and frailty that may not be appropriately reflected in the elderly frail, or perhaps the reduced physiological reserves in the very elderly require more active support in an ICU in order to survive.

Table 3. ICU interventions for the very elderly patients $(\geq 80$ years $)$

\begin{tabular}{ll}
\hline Interventions & $\begin{array}{l}\text { Aged } \geq 80 \text { years } \\
\text { n }(\%)\end{array}$ \\
\hline Arterial Line & $852(20.6)$ \\
Non-Invasive ventilation & $360(8.7)$ \\
Invasive ventilation & $860(20.8)$ \\
Renal Replacement Therapy & $190(4.6)$ \\
Temporary Cardiac Pacing Electrode & $90(2.2)$ \\
Intra-Aortic-Balloon Catheter & $22(0.5)$ \\
External Ventricular Drain & $3(0.1)$ \\
Bronchoscopy & $1(0.0)$ \\
Intracranial pressure monitoring device & $2(0.0)$ \\
Cardiac Output Monitoring & $34(0.8)$ \\
Total & 2,414 \\
\hline
\end{tabular}

Table 4. Co-morbidities, for all age groups, for ICU admissions between 2000 to 2015

\begin{tabular}{|c|c|c|c|c|c|c|c|c|c|c|}
\hline Age & $\begin{array}{l}\text { Chronic } \\
\text { respiratory } \\
\text { disease } \\
\mathbf{n}(\%)\end{array}$ & $\begin{array}{l}\text { Chronic } \\
\text { cardiovascular } \\
\text { disease } \\
\text { n }(\%)\end{array}$ & $\begin{array}{l}\text { Immune } \\
\text { Disease } \\
\text { n (\%) }\end{array}$ & $\begin{array}{l}\text { Immunosuppressed } \\
\text { n (\%) }\end{array}$ & 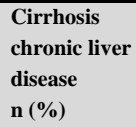 & $\begin{array}{l}\text { Metastases } \\
\text { n (\%) }\end{array}$ & $\begin{array}{l}\text { Leukaemia } \\
\text { myeloma } \\
\text { n }(\%)\end{array}$ & $\begin{array}{l}\text { IDDM } \\
\text { n }(\%)\end{array}$ & $\begin{array}{l}\text { Chronic } \\
\text { renal } \\
\text { failure } \\
n(\%)\end{array}$ & $\begin{array}{l}\text { Lymphoma } \\
\text { n (\%) }\end{array}$ \\
\hline$<20$ & - & - & $9(2.2)$ & $16(3.9)$ & - & $2(0.5)$ & $6(1.4)$ & $31(7.5)$ & $2(0.5)$ & $1(0.2)$ \\
\hline $20-39$ & $45(1.0)$ & $37(0.8)$ & $83(1.9)$ & 115 (2.6) & $41(0.9)$ & $42(0.9)$ & $51(1.1)$ & 209 (4.7) & $65(1.5)$ & $19(0.4)$ \\
\hline $40-59$ & $273(3.1)$ & $272(3.1)$ & $169(1.9)$ & $368(4.1)$ & $334(3.8)$ & $244(2.7)$ & $147(1.7)$ & $543(6.1)$ & $356(4.0)$ & $93(1.0)$ \\
\hline $60-79$ & $964(6.3)$ & $1,080(7.2)$ & 255 (1.7) & 540 (3.6) & 244 (1.6) & $486(3.3)$ & 275 (1.8) & $1,173(7.9)$ & 705 (4.7) & $162(1.1)$ \\
\hline $80+$ & $265(6.4)$ & $348(8.4)$ & $41(1.0)$ & $78(1.9)$ & $31(0.7)$ & $121(2.9)$ & $64(1.5)$ & $172(4.2)$ & $108(2.6)$ & $24(0.6)$ \\
\hline
\end{tabular}

One of the more notable findings was that admissions from the ED increased while admissions from the OT and general wards decreased. This may reflect the challenge that Australian hospitals face on a daily basis, trying to balance the increasing number of elderly medical admissions from EDs ${ }^{[16]}$ with the simultaneous pressure to deal with elective surgery waiting lists. The increasing number of elderly emergency admissions may be related to factors such as it is often the "fall back" position when someone suffers an acute deterioration in their health. In the case of the very elderly, it may be the result of an acute condition such as infection or a fall; or the accumulation of the increasing number of chronic conditions or a combination of both.

The decrease in the percentage of admissions from the general wards may have been related to the increasing effectiveness of the Rapid Response System (RRS) ${ }^{[17]}$ which became more of a standard system in Australian hospitals over the time period of the study. Other factors may include an increase in ward-based care or maybe an increase in limitations of treatment in the very elderly.

As expected, the rates of chronic respiratory and cardiovascular failure were higher in the very elderly, related to the increasing incidence of related diseases in these organs, or just simply due to age-related deterioration of vital organs. Thus, the reduction in the incidence of IDDM and chronic renal failure is more difficult to explain. Perhaps many of these patients had already died as a result of these serious chronic conditions or because of the severity of their underlying illness, they were not considered suitable for admission to the ICU.

While the hospital and ICU mortality of the very elderly 
was higher than for younger patients, the overall ICU and hospital mortality decreased over the same period of time. This trend is consistent with that reported across many Australian ICUs ${ }^{[18]}$ and is probably related to the improved care provided in ICUs as well as earlier recognition and intervention of the common causes of admission such as sepsis and the widespread implementation of RRSs in Australian hospitals. It may also be due to the increased acceptance of high level and life prolonging interventions in the very elderly, regardless of their age.

While the increased aggressive treatment of the very elderly may produce improved short-term improvement in mortality, there is increasing evidence that the longer-term mortality after hospital discharge is very high in the very elderly ${ }^{[19-21]}$ and that the incidence of serious complications after hospital discharge is also very high. ${ }^{[22-24]}$ As critical care medicines' gain more knowledge about longer-term outcomes, it will be useful to include information about longer-term outcomes.

At the same time, it is important to acknowledge that age alone is not a strong predictive factor of outcomes. ${ }^{[25-28]}$ There is increasing evidence that intensive care may need to use other prognostic indicators as well as age, such as the level of frailty. ${ }^{[29,30]}$ Moreover, the increased incidence of co-morbidities in the elderly also contributes to the increased mortality and the degree of frailty. ${ }^{[31]}$

While age may not in itself be a good predictor of short and longer-term outcome in patients who are managed in an ICU, when it is used in combination with tools, which measure the sum of the chronic conditions such as frailty, it can be an accurate indicator of both short and long-term outcomes of a person. ${ }^{[29,32-34]}$ Interestingly, measures of frailty became part of the national ANZICS data collection in Australian ICUs in late 2017. ${ }^{[35,36]}$

The gradual increase in the age of our patients challenges us to consider factors such as the use of prognostic tools such as APACHE $^{[37]}$ and SAPS ${ }^{[10]}$ as well as the way we estimate the performance of ICUs such as by comparing the estimated against the actual mortality based on these scores. In future, the value of interventions in ICU may be based not only on whether the patient survived to hospital discharge, but more on longer term outcomes, including mortality and quality of life. It may also be that the contribution of chronic diseases to prognostic scores underestimated survival when tools such as APACHE and SAPS were first developed and that we should review our way of determining prognosis and ICU performance in terms of tools which incorporate more information about the chronic health status as well as including longer-term outcomes. This is important for not only evaluating the impact of an ICU intervention but also as a basis for more engagement with society and individuals about goals of care in the light of longer-term post hospital outcomes. The use of age together with other measures such as frailty could also increase the role of intensive care in end of life discussions.

\subsection{Strengths of the study}

To our knowledge, this is the first Australian study to specifically describe age related trends of ICU admissions among very elderly patients. It highlights the need for ICUs to review the nature and trends of their age-related trends, especially when considering issues such as longer-term mortality and quality of life outcome rather than simply using ICU and hospital mortality when determining indications for admission and a basis for more realistic discussions about goals of care with patients and those who care for them.

\subsection{Potential weakness of the study}

The study in question has several limiting factors, the most important of which is that it is retrospective and undertaken in a single adult ICU in Australia and, as such, may not be generalizable. The study also ignored the reasons and clinical diagnoses between the admission to the hospital and the ICU.

\subsection{Implication for ICU's clinicians and policy makers}

Currently, prognosis and outcomes of patients admitted to the ICU are mainly based on pathophysiological on admission to hospital APACHE. ${ }^{[37]}$ There is also a need to examine more closely the short and longer-term outcomes of elderly patients with a poor prognosis. The prognosis of patients depends on factors such as the interrelationship between frailty, the patients' age and their pre-existing diseases and these are likely to be considered more by intensive care clinicians when considering admission criteria and outcomes. ${ }^{[38-40]}$

This study has attempted to emphasise the importance of considering the chronic health status of patients being considered for admission to the ICU. If Information about the chronic health status influences the prognosis and outcome of the elderly being considered for admission to an ICU it will become an increasingly important for policy makers, the funders of health care and most importantly for the patients themselves.

\section{Conclusions}

As the general population ages, the age of patients in intensive care has increased. This represents a different population from the one on which we base much of our practice. The elderly frail have serious and natural decline in their physiology and almost always have chronic health conditions, both of which predispose to the acute reason for admission such 
as falls or infection, as well as compromising their ability to recover from what could otherwise be minor acute insults. Hence, they have longer lengths of hospital and ICU stay. We may need to address the way we estimate severity of illness with more weight placed on the chronic health status and include concepts such as frailty when assessing outcomes and indications for ICU admission. The acute reasons for hospital and ICU admission may increasingly become, not just something that can be treated with conventional management, but also a marker of increasing ageing and frailty. Because the underlying age-related deterioration of the el- derly frail is naturally progressive and largely irreversible, the role of intensive care could become more important when discussing goals of care issues with patients and their carers.

\section{ACKNOWLEDGEMENTS}

We are grateful to the data-manager of Liverpool intensive care unit especially Mrs Suzanne Weightman who helped with retrieving data.

\section{CONFlicts OF INTEREST Disclosure}

The authors declare they have no conflicts of interest.

\section{REFERENCES}

[1] Ferrucci L, Giallauria F, Guralnik JM. Epidemiology of aging. Radiol Clin North Am. 2008; 46(4): 643-652. PMid: 18922285 https://doi.org/10.1016/j.rcl.2008.07.005

[2] Department of economic and social affairs. United Nations: World population ageing: 1950-2050. Available from: http://www.un.o rg/esa/population/publications/worldageing19502050

[3] Australian Bureau of Statistics. Population by age and sex, Australia, states and territories. 1301.0-Australian demographic statistics. Canberra; 2017.

[4] Lee SH, Lee WT, Ju S, et al. Outcome of very elderly ( $\geq 80$ years) critical-ill patients in a medical intensive care unit of a tertiary hospital in Korea. Korean J Intern Med. 2017; 32: 2015-331. PMid: 28651311. https://doi.org/10.3904/kjim.2015.331

[5] Kim J, Lee J, Choi S, et al. Trends in the use of intensive care by very elderly patients and their clinical course in simple tertiary hospital in Korea. Korean Crit Care Med. 2016; 31(1): 25-33. https://doi.org/10.4266/kjccm.2016.31.1.25

[6] Becker S, Muller J, Heer G, et al. Clinical characteristic and outcome of very elderly patients $>90$ years in intensive care: a retrospective observation study. Ann Intensive Care. 2015; 5(53). https://doi.org/10.1186/s13613-015-0097-1

[7] Lerolle N, Trinquart L, Bornstain C, et al. Increased intensity of treatment and decreased mortality in elderly patients in an intensive care unit over a decade. Crit Care Med. 2010; 38(1): 50-64. PMid: 19633539. https://doi.org/10.1097/CCM.0b013e31 $81 \mathrm{~b} 088 \mathrm{ec}$

[8] Hass LEM, Karakus A, Holman R, et al. Trends in hospital and intensive care admissions in the Netherlands attributable to the very elderly in an ageing population. Crit Care. 2015; 19: 353. PMid: 26423744. https://doi.org/10.1186/s13054-015-1061-z

[9] Knaus WA, Draper EA, Wagner DP, et al. APACHE II: a severity of disease classification system. Crit Care Med. 1985. PMid: 3928249. https://doi.org/10.1097/00003246-198510000-00009

[10] Le Gall JR, Lemeshow S, Saulnier F. A new simplified acute physiology score (SAPS II) based on a European/North American multicenter study. JAMA. 1993; 270(24): 2957-63. PMid: 8254858 https://doi.org/10.1001/jama.1993.03510240069035

[11] Fuchs L, Chronaki CE, Park S, et al. ICU admission characteristics and mortality rates among elderly and very elderly patients. Intensive Care Med. 2012; 38(10): 1654-61. PMid: 22797350. https://doi.org/10.1007/s00134-012-2629-6
[12] Adhikari NKJ, Flower RA, Bhagwanjee S, et al. Critical care and the global burden of critical illness in adults. Lancet. 2010; 375: 13391346. https://doi .org/10.1016/S0140-6736(10)60446-1

[13] Diem SJ, Lantos JD, Tulsky JA. Cardiopulmonary resuscitation on television: Miracles and misinformation. N Engl J Med. 1996; 334: 1578-1582. PMid: 8628340. https://doi.org/10.1056/NEJM 199606133342406

[14] Hillman K. A good life to the end: taking control of our inevitable journey through ageing and death. Allen and Unwin; 2017. 165-174 p.

[15] Nguyen YL, Angus D, Boumendil A, et al. The challenge of admitting the very elderly to intensive care. Ann Intensive Care. 2011; 1: 29. PMid: 21906383. https ://doi.org/10.1186/2110-582 0-1-29

[16] Lowthian JA, Crutis AJ, Jolley DJ, et al. Demand at the emergency department front door:10-year trends in presentations. MJA. 2012; 19 (2): 128-132. https://doi.org/10.5694/mja11.10955

[17] Jones DA, DeVita MA, Bellomo R. Rapid-response teams. New Engl J Med. 2011; 365: 139-146. PMid: 21751906. https://doi.org/ 10.1056/NEJMra0910926

[18] Kaukonen KM, Bailey M, Suzuki S, et al. Mortailty related to severe sepsis and septic shock among critically ill patients in Australia and New Zealand, 2000-2012. JAMA. 2014; 311(13): 1308-1316. PMid: 24638143. https://doi.org/10.1001/jama.2014.2637

[19] Brummel NE, Bell SP, Girard TD, et al. Frailty and Subsequent Disability and Mortality among Patients with Critical Illness. Am J Respir Crit Care Med. 2017; 196: 64-72. PMid: 27922747. https ://doi.org/10.1164/rccm.201605-09390C

[20] Ferrante LD, Pisani MA, Murphy TE, et al. Functional trajectories among older persons before and after critical care illness. JAMA Intern Med. 2015; 175(4): 523-529. PMid: 25665067. https: //doi.org/10.1001/jamainternmed.2014.7889

[21] Spragg RG, Bernard GR, Checkley W, et al. Beyond mortality: future clinical research in acute lung injury. Am J Respir Crit Care Med. 2010; 181(10): 1121-1127. PMid: 20224063. https: //doi.org/10.1164/rccm.201001-0024WS

[22] Mukhopadhyay A, Tai BC, See KC, et al. Risk factors for hospital and long-term mortality of critical ill elderly admitted to an intensive care unit. Biomed Res Int. 2014. https : //doi . org/10.1155/20 $14 / 960575$

[23] Roch A, Wiramus S, Pauly V, et al. Long-term outcome in medical patients aged 80 or over following to an intensive care unit. Crit Care. 2011; 15(1): R36. PMid: 21261976. https ://doi .org/10.1186/ cc9984 
[24] Andersen FH, Flaatten H, Klepstad P, et al. Long-term survival and quality of life after intensive care for patients 80 years of age or older. Ann Intensive Care. 2015; 5: 13. PMid: 26055187. https://doi.org/10.1186/s13613-015-0053-0

[25] Kirshenbom D, Ben-Zaken Z, Alibilya N, et al. Older age, comorbid illness, and injury severity affect immediate outcome in elderly truama patients. J Emerg Trauma Shock. 2017; 10(3): 146-150. PMid: 28855778. https://doi.org/10.4103/JETS.JETS_62_16

[26] Boumendil A, Somme D, Garrouste-Orgeas M, et al. Should elderly patients be admitted to the intensive care unit? Intensive Care Med. 2007; 33: 1252-1262. PMid: 17404703. https ://doi.org/10.1 007/s00134-007-0621-3

[27] Nicolas F, Le Gall JR, Alperovitch A, et al. Influence of patients' age on survival, level of therapy and length of stay in intensive care units. Intensive Care Med. 1987; 13: 9-13. PMid: 3558942. https://doi.org/10.1007/BF00263549

[28] Rockwood K, Noseworthy TW, Gibney RT, et al. One-year outcome of elderly and young patients admitted to intensive care units. Crit Care Med. 1993; 21: 687-691. PMid: 8482089. https : //doi.org/10.1097/00003246-199305000-00011

[29] Bagshaw SM, Stelfox HT, McDermid RC, et al. Association between frailty and short- and long-term outcomes among critically ill patients: A multicentre prospective cohort study. Can Med Assoc J. 2014; 186(2): E95-E102. PMid: 24277703. https ://doi .org/10 $.1503 / \mathrm{cmaj} .130639$

[30] Bagshaw SM, Stelfox HT, Johnson JA, et al. Long-term association between frailty and health-related quality of life among survivors of critical illness: A prospective multicenter cohort study. Crit Care Med. 2015; 43(5): 973-82.

[31] Buckinx F, Rolland Y, Reginster JY, et al. Burden of frailty in the elderly population: perspective for a public health challenge. Arch Public Health. 2015; 73(1): 1-7. PMid: 25866625. https: //doi.org/10.1186/s13690-015-0068-x
[32] Le Maguet P, Roquilly A, Lasocki S, et al. Prevalence and impact of frailty on mortality in elderly ICU patients: A prospective, multicenter, observational study. Intensive Care Med. 2014; 40(5): 674-82. https ://doi.org/10.1007/s00134-014-3253-4

[33] Muscedere J, Waters B, Varambally A, et al. The impact of frailty on intensive care unit outcomes: a systematic review and metaanalysis. Intensive Care Med. 2015; 43: 1105-1122. PMid: 28676896. https ://doi.org/10.1007/s00134-017-4867-0

[34] Flaatten H, De Lange DW, MoranBadi A, et al. The impact of frailty on ICU and 30-day mortality and the level of care in very elderly patients ( $\geq 80$ years). Intensive Care Med. 2017; 43(12): 1820-1828. PMid: 28936626. https://doi.org/10.1007/s00134-017-4 940-8

[35] Australian and New Zealand Intensive Care Society (ANZICS). ANZICS statement on care and decisions-making at the end of life for the critically ill (edition: 1.0). Melbourne: ANZICS; 2014.

[36] Australian and New Zealand Intensive Care Society (ANZICS). ANZ ICS core-adult patient database (version 5.4). ANZICS Centre for Outcome and Resource Evaluation; 2016.

[37] Knaus WA, Draper EA, Wagner DP, et al. APACHE II: a severity of disease classification system. Crit Care Med. 2015; 13(10): 818-829. https://doi.org/10.1097/00003246-198510000-00009

[38] Joynt G, Gomersall C, Tan P, et al. Prospective evaluation of patients refused admission to an intensive care unit: Triage, futility and outcome. Intensive Care Med. 2001; 27(9): 1459-65. PMid: 11685338. https://doi.org/10.1007/s001340101041

[39] Zampieri FG, Colombari F. The impact of performance status and comorbidities on the short-term prognosis of very elderly patients admitted to the ICU. BMC Anesthesiol. 2014; 14(1): 59. PMid: 25071415. https : //doi.org/10.1186/1471-2253-14-59

[40] Hillman K. The changing role of acute-care hospitals. Med J Aust. 1999; 170(7): 325. PMid: 10327976. 